\title{
Fractal signature analysis measures cancellous bone organisation in macroradiographs of patients with knee osteoarthritis
}

\author{
J C Buckland-Wright, J A Lynch, D G Macfarlane
}

\begin{abstract}
Objective-To determine whether fractal signature analysis (FSA) of digitised macroradiographs of knees quantifies alterations in trabecular structure in the tibial cancellous bone of osteoarthritic patients with either early or definite joint space narrowing compared with non-arthritic subjects.
\end{abstract}

Methods-90 osteoarthritic knees had macroradiographs at $\times 5$ magnification. Joint space width and FSA of horizontal and vertical trabecular organisation in the tibial subarticular cancellous bone were measured in the medial and lateral tibio-femoral compartments and compared to reference values obtained from the knees of 14 healthy non-arthritic volunteers, and to the subject's age and weight.

Results-Compared to the non-arthritic joints, FSA of the trabecular structure of the medial diseased compartment of the tibia was significantly different and correlated with the degree of joint space narrowing ( $P<0.003)$; FSA of horizontal trabecular structures decreased $(P<$ 0.001) in knees with early osteoarthritis (joint space $>3 \mathrm{~mm}$ ) and vertical trabecular FSA increased in knees with marked joint space narrowing (joint space $<3$ $\mathbf{m m})$. In the lateral compartment of the tibia, FSA did not show a difference between any of the categories. With increasing age of all subjects, the changes in FSA indicated a significant increase in the number of fine horizontal and vertical trabeculae. No correlation was found between the subjects' body weight and changes in the subarticular cancellous bone organisation.

Conclusions-FSA quantifies changes in cancellous bone organisation in knee osteoarthritis. In the diseased compartment, increased horizontal trabecular thickness occurred early and preceded the later changes in the vertical structures.

(Ann Rheum Dis 1996;55:749-755)

In evaluating the pathogenesis of osteoarthritis, studies have concentrated on the assessment of articular cartilage degeneration and loss, since this is considered to be the pathological hallmark of osteoarthritis. ${ }^{1}$ However, articular cartilage is intimately associated with subchondral bone. Together they act as a system that mediates and adapts to mechanical stress, to the extent that it is difficult to isolate events in one tissue compartment that do not affect the other. ${ }^{2}{ }^{3}$ Subchondral sclerosis, seen as an increase in the thickness of the subarticular cortex and cancellous bone, is attributed to the degeneration and loss of cartilage and the consequent increase in mechanical load upon the subjacent bone. ${ }^{45}$ To understand the processes involved in the dialogue between bone and cartilage, methods are required that will provide quantitative data on changes in subchondral cancellous bone from images of the bones of patients. Although several techniques have been used to measure the increase in bone mineral density in osteoarthritis joints, ${ }^{6}$ it is clear that these methods alone are insufficient to determine the strength and solidity of cancellous bone, and that other techniques are needed to assess factors such as trabecular architecture.

We report the results of a new method for quantifying the trabecular organisation within the proximal tibia of patients with knee osteoarthritis. The detailed organisation of the bone was recorded by high definition macroradiography ${ }^{10}$ and quantified using a recently developed method of fractal signature analysis (FSA). ${ }^{11}$ The advantage of combining these two techniques is that the former records, with unusually good resolution, the fine detailed structural organisation of cancellous bone, which is then quantified by FSA. Fractal analysis measures the degree of "roughness" of an image of those structures, and also quantifies the change in roughness with alterations in spatial scale. ${ }^{13}$ Self similar images (looking the same at all magnifications) ${ }^{14}$ are said to be "fractal" and have associated with them a fractal dimension, between 2 and 3 for a surface. ${ }^{13}$ When the pattern of a structure has altered at a particular size or sizes so as to be no longer self similar, the "fractal signature" of its image quantifies the alteration in the fractal dimension of the structure, and the size(s) at which those changes have occurred. ${ }^{11}{ }^{12}$ The fractal dimension, and similarly the fractal signature, has no units since it is calculated from the ratio of two areas. ${ }^{13}$ The fractal dimension of cancellous bone assesses the composite nature of the tissue, which is determined principally by trabecular number, spacing, and cross connectivity, ${ }^{15}$ features which are here referred to as trabecular structures. Studies to determine the components of cancellous bone organisation measured by FSA have shown the method to be sensitive to alterations in the trabecular anisotropy and alterations in bone volume and trabecular thickness. ${ }^{16}$ The method of FSA provides more information than the mean fractal dimension employed by 
previous investigators ${ }^{12}{ }^{13}$ which only quantifies the overall appearance of cancellous bone, whereas FSA measures separately the fractal dimension of the horizontal and vertical trabecular structures within the cancellous bone ${ }^{1112}$ and quantifies how the fractal dimension varies with the size of the structures.

Recently, we have formally evaluated the pattern of articular cartilage loss in patients with knee osteoarthritis, detected as joint space narrowing in macroradiographs of the knee in the standing semiflexed and weight bearing tunnel views. ${ }^{17}$ Three patterns of joint space narrowing were found: (1) that observable in both the views; (2) that observable in mainly the standing semiflexed view; and (3) that observable in mainly the weight bearing tunnel view. The aim of this study was to determine whether there was any association between the cancellous bone organisation within the tibia and the degree and pattern of joint space narrowing measured from macroradiographs of the knee in the standing semiflexed and weight bearing tunnel views; as well as to determine whether there was any relation with the subjects' body weight and age.

\section{Methods}

PATIENTS AND REFERENCE GROUP

Thirty three patients with early symptomatic knee osteoarthritis were recruited from those attending the rheumatology clinic. Nine men
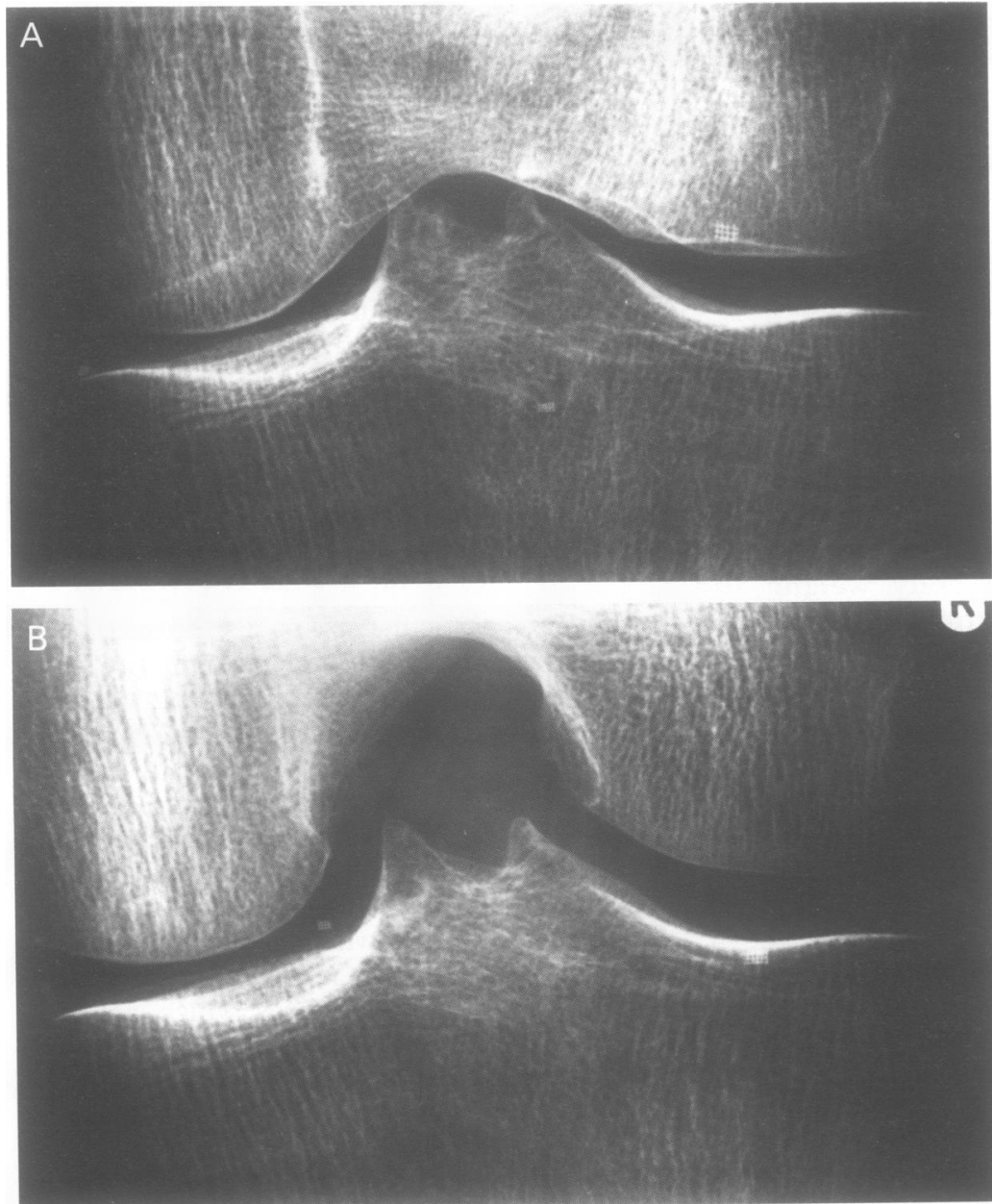

Figure 1 Part of the macroradiographs of osteoarthritic knee joints in the weight bearing standing $(A)$ and modified tunnel $(B)$ views. The grids are used to determine the radiographic magnification (original magnification $\times 5$, reproduced $\times 1.3$ ). and 24 women patients had a mean (SD) age of 58.5 (9.4) years, and a mean (SD) disease duration, based on the duration of pain in the worst, that is the most painful, knee of 24 (36) months and a mean (SD) weight of 84.5 (16.2) kg. On conventional radiography, all had evidence of osteophytes and either subchondral sclerosis or joint space narrowing in the most painful knee. All were weighed and carefully examined clinically to exclude other types of arthritis, evidence of trauma, previous surgical intervention, or treatment with corticosteroids. All were seronegative for rheumatoid factor and had an erythrocyte sedimentation rate within the normal range.

As ethics considerations precluded taking $x$ rays of non-diseased age and sex matched hospital attenders, macroradiographs of 14 healthy, non-arthritic volunteers (seven men and seven women), mean age 37 (10.6) years and mean weight $76.3(11.7) \mathrm{kg}$, were obtained from medical and laboratory staff. The dimensions of the radiographic features measured provided a reference range for the anatomy of healthy knee joints and is referred in the text as the reference value.

PREPARATION OF MACRORADIOGRAPHS

Macroradiographs at $\times 5$ magnification ${ }^{9}{ }^{10}$ were prepared of the knees in both the standing semiflexed and weight bearing tunnel views. ${ }^{17}$ Radiographic magnification for computing the size of $x$ ray features within the joint was determined by placing fine wire meshes on the knee's anterior and posterior surfaces before radiography, and from measurements taken of the focus to knee and focus to film distance following radiography.

\section{Standing semiflexed view}

In the standing semiflexed view ${ }^{9}$ the surface of the tibial plateau is horizontal with the joint positioned close to the normal anatomical standing position and to the region of major contact stresses in the tibio-femoral articulation. ${ }^{18}$ The centre of the joint, defined by the joint space, was aligned with the centre of the $x$ ray beam with the aid of a crossoptic laser. Each knee was flexed until the tibial plateau was horizontal relative to the floor, parallel to the central $x$ ray beam and perpendicular to the $x$ ray film. The degree of flexion varied between patients and ranged between $179^{\circ}$ and $160^{\circ}$ due to the inherent variation in the angle of inclination of the tibial plateau among patients. Fluoroscopy was used to ensure that the precise position of the knee was obtained and that the tibial spines were centrally placed relative to the femoral notch (fig 1A).

\section{Weight bearing tunnel view}

This radiographic position of the knee differs from the standard tunnel view ${ }^{19}$ which is taken in the unloaded position. The angle of flexion, used in this study, of $130^{\circ}$ subtended by the tibia and femur at the joint, is similar to that described for the standard tunnel view. ${ }^{19}$ The view assessed alteration to cartilage thickness over the popliteal surface of the condyles. With the aid of the laser and fluoroscopy, the 
position of the knee was adjusted to ensure that the tibial plateau was horizontal and perpendicular to the $x$ ray plate and that the tibial spines were centrally placed relative to the femoral notch (fig 1B).

\section{IMAGE ANALYSIS: DIGITISATION OF}

MACRORADIOGRAPHS

The macroradiographs were digitised using a CCD camera (Kodak Megaplus 1.2) linked through an interface board on a display system in an IBM PC-AT 80486 computer. By adjusting the camera to film distances, the effective pixel size was set to $0.06 \mathrm{~mm}$ (corresponding to $0.30 \mathrm{~mm}$ on the film when radiographic magnification was $\times 5$ ). The digital images were written to a SUN SPARC station IPX (SUN Microsystems) and programs written in $\mathrm{C}$ were used to measure joint space width ${ }^{17}{ }^{20}$ and to calculate the fractal signature ${ }^{11}{ }^{12}$ for regions of interest in the images.

\section{Measurement of joint space width}

For each compartment, the computer automatically traced the edge of the condyle and for the tibial plateau the computer traced the line of the brightest pixels, that is, the superior margin of the subchondral cortex. Within the lines defining the compartmental joint space, the computer calculate a series of circles, the diameter of which defined the joint space width and identified and measured the minimum interbone distance considered the most representative measure of cartilage loss in the tibio-femoral compartment. ${ }^{1}$ The accuracy and reproducibility of the radiographic procedure and automatic method of joint space width measurement, and the reproducibility of patient repositioning in the standing and tunnel views, gave a coefficient of variation for joint space width measurement in the medial compartment of $1.2 \%$ and in the lateral compartment of $3.8 \% .{ }^{20}$ All assessments were carried out by one observer whose coefficient of variation for repeat measures for

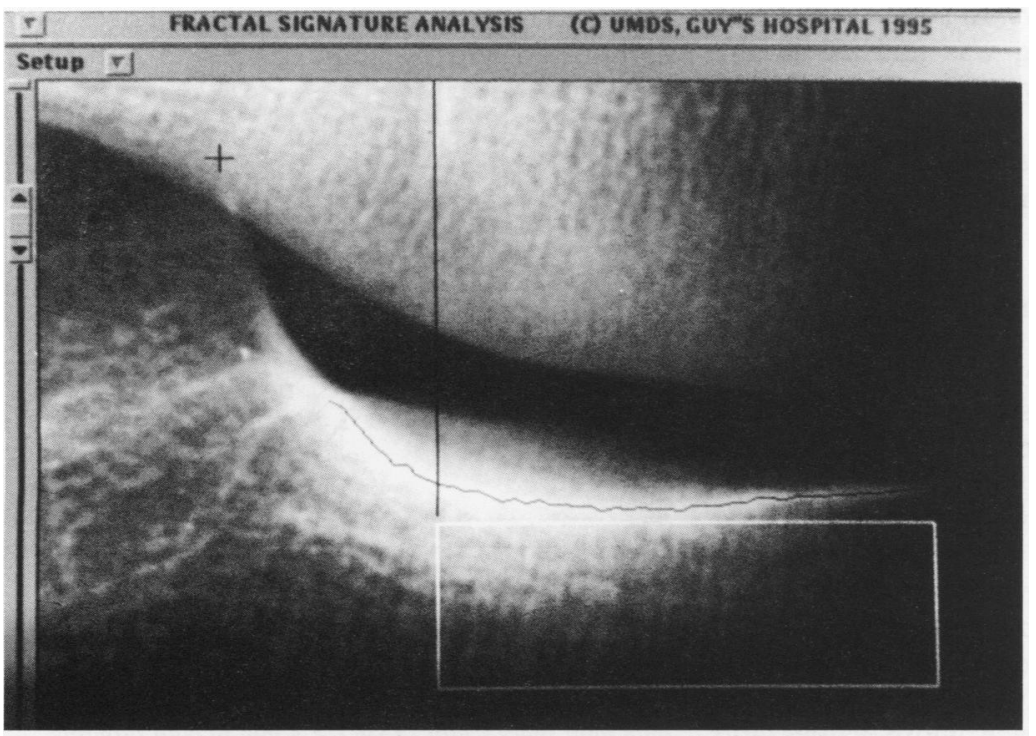

Figure 2 Part of a computer screen showing a digitised macroradiograph of an osteoarthritic knee in the standing view. The region of interest used for calculating the fractal signature of the tibial cancellous bone in the medial compartment is outlined in white; the horizontal black line defines the floor the tibial plateau. the medial compartment was $0.6 \%$ and for the lateral compartment $3.6 \% .^{20}$

\section{Measurement of subarticular cancellous bone}

Fractal analysis is a robust method ${ }^{2122}$ which is independent of a range of factors that are susceptible to variation during routine radiographic procedures, that is, the effect of radiographic magnification and projection geometry, ${ }^{111222}$ changes in object or patient position, ${ }^{11-152122}$ and variations in the sensitometric properties of radiographs such as film contrast and mean density. ${ }^{11222}$ The region of interest (size after correction for radiographic magnification: $20 \times 6 \mathrm{~mm}$ ) selected within the digitised macroradiographs of the medial and lateral compartments of the tibia is shown in fig 2. Since tibial trabecular thickness and medullary space size is in general within $0.06 \mathrm{~mm}$ and $1.2 \mathrm{~mm},{ }^{23}$ the fractal signature calculations were carried out on data ranging from 1 to 20 pixels, corresponding to a scale of image feature sizes from $0.06 \mathrm{~mm}$ to $1.2 \mathrm{~mm}$. We assessed accuracy by determining the variations in measurements of FSA for horizontal and vertical structures from the macroradiograph of a tibia redigitised six times, and for test-retest reliability by digitising the macroradiographs of a postmortem tibia repositioned and reradiographed six times. The coefficient of variation for test retest for FSA measurements was $2.1 \% .^{12}$

ANALYSIS OF THE DATA

To evaluate the effect of articular cartilage loss, measured as joint space narrowing, upon the subarticular cancellous bone, each knee was grouped according to the degree of joint space narrowing present in the diseased compartment. We used a method described previously ${ }^{17}$ to evaluate the relative contribution of the standing semi-flexed and tunnel views to joint space width assessment in knee osteoarthritis, a box analysis was set up with the two axes representing the standing and tunnel view joint space width measurements. Based on the criteria of Alhback ${ }^{24}$ and Leach et al ${ }^{25}$ for defining knee osteoarthritis, patients' knees were grouped according to whether or not they had definite joint space narrowing, that is, a joint space width $<3 \mathrm{~mm}$.

The differences in the fractal signature (FS) between the reference group and osteoarthritic knees and between osteoarthritic knee subgroups were assessed for significance using multivariate analysis of variance (MANOVA) with repeat measures. To examine the associations between FSA and body weight and age in knee osteoarthritis patients and the non-arthritic reference group, Kendall's $\tau c$ was used. The significance level for all statistical tests was set at $\mathbf{P}=0.05$.

\section{Results}

JOINT SPACE WIDTH

foint space width reference range

The mean (SD) for the joint space width measurements in the medial and lateral tibiofemoral compartments of the healthy knee group are given in the table. 
Foint space width (FSW) of the medial and lateral tibiofemoral compartments of the reference group and of the osteoarthritic (OA) knees subdivided on the basis of the degree of joint space narroeing in the standing semiflexed and tunnel views of the knee. Refer for an explanation of the $O A$ knee subgroups

\begin{tabular}{|c|c|c|c|c|c|c|}
\hline & \multirow[b]{2}{*}{$n$} & \multirow[b]{2}{*}{$\begin{array}{l}\text { Age median } \\
\text { (interquartile } \\
\text { range) }\end{array}$} & \multicolumn{2}{|c|}{ Medial tibiofemoral $\mathcal{F S W}(\mathrm{mm})$} & \multicolumn{2}{|c|}{ Lateral tibiofemoral $\mathfrak{F S W}(\mathrm{mm})$} \\
\hline & & & $\begin{array}{l}\text { Standing } \\
\text { median } \\
\text { (interquartile } \\
\text { range) }\end{array}$ & $\begin{array}{l}\text { Tunnel median } \\
\text { (interquartile } \\
\text { range) }\end{array}$ & $\begin{array}{l}\text { Standing median } \\
\text { (interquartile } \\
\text { range) }\end{array}$ & $\begin{array}{l}\text { Tunnel median } \\
\text { (interquartile } \\
\text { range) }\end{array}$ \\
\hline Reference values & 28 & $34(25-48)$ & $\begin{array}{l}4.16 \\
(3.69-4.63)\end{array}$ & $\begin{array}{l}4.19 \\
(3.98-5.02)\end{array}$ & $\begin{array}{l}1.55 \\
(1.06-2.60)\end{array}$ & $\begin{array}{l}5.14 \\
(4.57-5.47)\end{array}$ \\
\hline All OA knees & 66 & $60(54-66)$ & $\begin{array}{l}3.14 \\
(2.43-3.95)\end{array}$ & $\begin{array}{l}3.50 \\
(2.51-4.24)\end{array}$ & $\begin{array}{l}2.18 \\
(1.61-3.47)\end{array}$ & $\begin{array}{l}4.32 \\
(3.74-4.96)\end{array}$ \\
\hline $\begin{array}{l}\text { OA knee subgroups } \\
\text { (1) JSW > } 3 \mathrm{~mm} \text { standing and } \\
\text { tunnel }\end{array}$ & 28 & $58(48-64)$ & $\begin{array}{l}3.80 \\
(3.56-4.08)\end{array}$ & $\begin{array}{l}4.14 \\
(3.65-4.59)\end{array}$ & $\begin{array}{l}2.16 \\
(1.65-3.72)\end{array}$ & $\begin{array}{l}4.72 \\
(4.21-5.27)\end{array}$ \\
\hline $\begin{array}{l}\text { (2) } \mathrm{JSW}<3 \mathrm{~mm} \text { in standing and } \\
\text { tunnel }\end{array}$ & 17 & $61(55-64)$ & $\begin{array}{l}2.58 \\
(1.80-2.98)\end{array}$ & $\begin{array}{l}2.89 \\
(2.50-2.95)\end{array}$ & $\begin{array}{l}2.26 \\
(1.77-2.92)\end{array}$ & $\begin{array}{l}3.90 \\
(3.62-4.41)\end{array}$ \\
\hline (3) $\mathrm{JSW}<3 \mathrm{~mm}$ in standing & 5 & $54(53-74)$ & $\begin{array}{l}1.02 \\
(0.48-2.83)\end{array}$ & $\begin{array}{l}4.67 \\
(3.89-5.62)\end{array}$ & $\begin{array}{l}1.25 \\
(0.83-2.05)\end{array}$ & $\begin{array}{l}4.74 \\
(4.46-5.61)\end{array}$ \\
\hline (4) JSW < 3 in tunnel & 16 & $60(54-67)$ & $\begin{array}{l}2.69 \\
(1.59-2.71)\end{array}$ & $\begin{array}{l}0.99 \\
(0.40-2.49)\end{array}$ & $\begin{array}{l}2.23 \\
(1.21-3.86)\end{array}$ & $\begin{array}{l}3.73 \\
(2.21-4.95)\end{array}$ \\
\hline
\end{tabular}

\section{Osteoarthritic knees}

Compared to the reference values, all patients with knee osteoarthritis had significant narrowing of joint space width in the medial compartment of the knees, in both the standing and tunnel views of the knees $(P<$ 0.0001 ) (table). By contrast, in the lateral compartment joint space width measurements were not statistically significant different from the reference value (table). Thus medial compartment joint space width measurements were significantly narrower than that in the lateral compartment in both standing semiflexed and tunnel views $(P<0.0001)$.

\section{Medial tibio-femoral compartment}

The results of the analysis to evaluate the degree of joint space narrowing in the standing and tunnel views of the diseased medial compartment is shown in the table. The mean joint space width in subgroup 1 was significantly smaller $(P<0.007)$ than that of the reference value but only in the standing semiflexed view. This group was judged to have minimal joint space narrowing. Subgroup 2 had definite joint space narrowing in both the standing and tunnel views. In subgroups 3 and 4 , joint space narrowing was marked in the standing and tunnel views respectively.

Lateral tibio-femoral compartment

Joint space width in this compartment was found to be similar in all subgroups (table).

COMPARISON BETWEEN JOINT SPACE WIDTH AND TIBIAL CANCELLOUS BONE ORGANISATION

Medial compartment of tibia

In all osteoarthritic knees as a group, a positive correlation was obtained between the values for decreased joint space width, recorded in the standing and tunnel views ( $\tau c=0.223$, giving $P<0.003$ ), and the significant decrease in the fractal signature (FS) for horizontal trabecular structures ranging in size between 0.60 and $0.90 \mathrm{~mm}$. A weaker inverse correlation $(\tau \mathrm{c}=$ 0.157 , giving $P<0.035$ ) was obtained between the decrease in joint space width values and an increase in the FS for vertical trabecular structures ranging in size between 0.66 and $0.72 \mathrm{~mm}$.
Horizontal trabecular structures

The FSA for horizontal trabecular structures in the reference group of knees and in the osteoarthritic knee subgroups 1,2 , and 4 are shown in fig 3. The results of the FSA for subgroup 3 were similar to those in subgroup 2 . In view of the small number of cases no statistical analysis was undertaken of the data in subgroup 3. In the osteoarthritis knee subgroup 1 (joint space $>3 \mathrm{~mm}$ ) the FS for horizontal structures, ranging in size between 0.36 and $0.66 \mathrm{~mm}$, was lower $(P<0.001)$ than the value for the reference group. The FS for horizontal structures was found not to be significantly different between the remaining osteoarthritic knee subgroups.

\section{Vertical trabecular structures}

The FSA for vertical trabecular structures in the reference group of knees and in the osteoarthritic knee subgroups 1,2 , and 4 are shown in fig 4. As for horizontal trabecular structures, the results of the FSA for subgroup 3 were similar to those of subgroup 2 . The FS for vertical trabecular structures in the reference group did not differ from that obtained from macroradiographs of knees with early osteoarthritis (joint space $>3 \mathrm{~mm}$ ), but

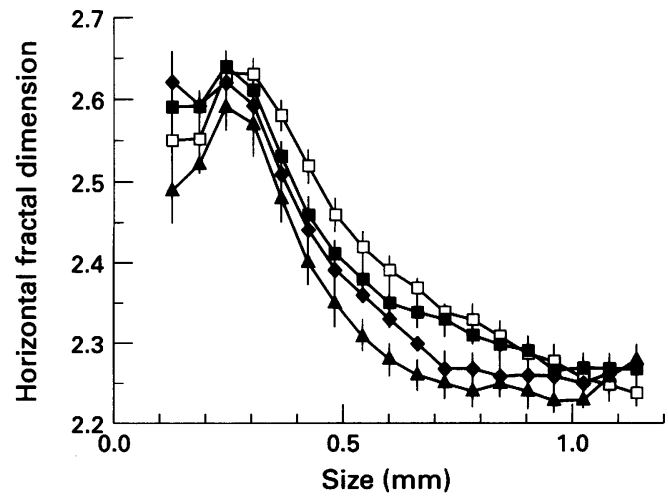

Figure 3 The mean (SE) fractal signature for horizontal trabecular structures in the medial compartment of the tibia of the reference group ( $\square$ ) and in osteoarthritic (OA) knees with joint space width (FSW) $>3 \mathrm{~mm}$ in both standing and tunnel views [subgroup 1 (1)], OA knees with $7 S W$ $<3 \mathrm{~mm}$ in both standing and tunnel views [subgroup 2 $(\diamond)]$, and $O A$ knees with $¥ S W<3 \mathrm{~mm}$ in the tunnel view only [ subgroup 4 ( $\triangle)$ ]. 
tended to differ from those with more marked joint space loss in subgroup 2 (joint space $<3$ $\mathrm{mm}$ ) in the size range of structures around $0.77 \mathrm{~mm}$. It is in the patients with cartilage loss in principally in the tunnel view, subgroup 4, that the FSA for vertical trabecular structures showed the greatest increase $(P<0.001)$ in the size range above $0.6 \mathrm{~mm}$.

\section{Lateral compartment of tibia}

The FS for horizontal and vertical trabecular structures in this region of the tibia was found to be similar in all groups.

EFFECT OF AGE AND BODY WEIGHT

In knees from both the non-arthritic healthy reference group and osteoarthritis patients, the subarticular cancellous bone in the medial and lateral compartments of the tibia showed an increase in the FS which correlated with the subject's age (fig 5 ).

In the medial compartment of the nonarthritic knees, the correlation between age and vertical trabecular structures was weak and occurred in the size range 0.18 to $0.24 \mathrm{~mm}$ ( $\tau \mathrm{c}$ $=0.25$ to 0.30 , giving $P$ values of $<0.03$ to $<$ 0.05 ), whereas the correlation was stronger for the horizontal structures in the size range 0.18 to $0.30 \mathrm{~mm}$ ( $\tau \mathrm{c}=0.28$ to 0.38 , giving $P$ values of $<0.01$ to $<0.03)$. In the lateral compartment of the tibia, conversely, the vertical structures showed a strong positive correlation with age in the size range 0.18 to $0.30 \mathrm{~mm}$ ( $\tau c=0.031$ to 0.41 , giving $P$ values of $<0.03$ to $<0.005)$ and a weaker correlation for horizontal structures over the same size range $(\tau c=$ 0.31 to 0.37 , giving $P$ values of $<0.01$ to $<$ 0.03).

In the medial compartment of osteoarthritic knees, the correlation between trabecular structures and age was weaker than that found in the non-arthritic group and involved the fine structures in both horizontal [size range 0.18 to $0.30 \mathrm{~mm}$ ( $\tau \mathrm{c}=0.18$ to 0.32 , giving $P$ values of $<0.07$ to $<0.02)$ ], and vertical structures [size range 0.18 to $0.24 \mathrm{~mm}(\tau \mathrm{c}=0.18$ to 0.27 , giving $P$ values of $<0.01$ to $<0.02$ )]. In the lateral compartment, the FS for the cancellous bone in the osteoarthritis knees was similar to that of the non-arthritic joints.

Although the mean age of non-arthritic reference group was less than the osteoarthritis

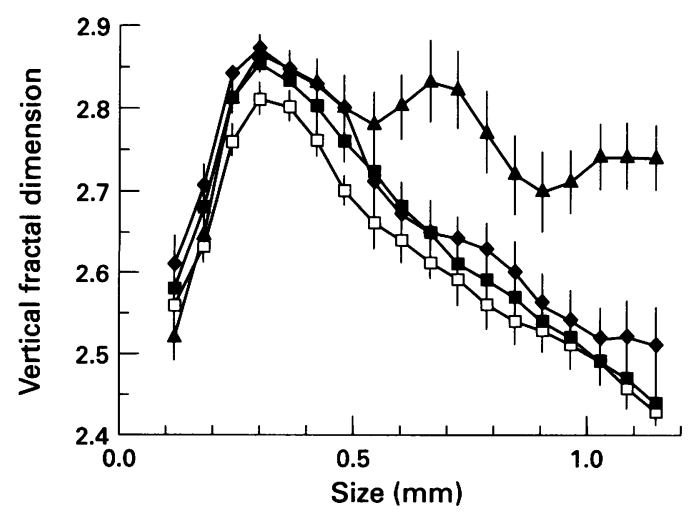

Figure 4 The mean (SE) fractal signature for vertical trabecular structures in the medial compartment of the tibia of the different subgroups of knees described in fig 3. subgroups (table), no statistical correlation was detected between the subjects' age and the FS for large trabecular structures (range 0.5 to 1.0 $\mathrm{mm})$. The FSA for large vertical trabecular structures in subgroup 1 was similar to that in the younger reference group, but statistically different to those in the similar aged subgroup 4, confirming that changes in the trabecular organisation at this scale were due to the effects related to joint space narrowing and not age.

No association was found between the body weight of the reference group and the osteoarthritis patients and the FS for horizontal and vertical trabecular structures in either of the compartments of the tibia.

\section{Discussion}

Fractal signature analysis of the cancellous bone organisation, recorded in macroradiographs of osteoarthritic knees, quantified changes in subarticular trabecular structure of the tibia. The trabecular structure was found to have altered in the medial diseased compartment only. In the lateral compartment of osteoarthritic knees, the cancellous bone organisation was similar to that of the healthy non-arthritic knees. In the medial compartment of osteoarthritic knees, the changes in the FS of trabecular features correlated with the degree of joint space loss, confirming the close association between these two tissue compartments. ${ }^{2}$ Significant changes in trabecular remodelling were detected with the onset of joint space narrowing observed in the standing view of knees with early osteoarthritis (joint space $>3 \mathrm{~mm}$ ). The earliest changes in the subchondral cancellous bone appeared as a decrease in the FS for the horizontal structures, consistent with an increase in the thickness of large horizontal trabeculae, ranging in size from 0.5 to $1 \mathrm{~mm}$. In knees with more advanced osteoarthritis and greater joint space loss, horizontal trabeculae were found to be thicker and closer together (fig 6). Preliminary FSA studies of these knees has shown such alteration in the trabecular structure to be statistically significant. ${ }^{26}$

In an earlier study ${ }^{17}$ of the knees evaluated in this investigation, knees with early osteoarthritis (joint space $>3 \mathrm{~mm}$ ) had increased subchondral cortical plate thickness. Coupling the findings of significant bone remodelling with early changes in cartilage thickness leads to the conclusion that in human knee osteoarthritis, subchondral cortical and cancellous bone remodelling appears as an early manifestation of osteoarthritis, a finding supported by results from both experimental animal work ${ }^{27}$ and observations in human hand and knee osteoarthritis ${ }^{17229}$ where subchondral bone formation occurred in association with early cartilage changes.

Significant changes in the vertical trabecular structures of the medial compartment were detected in osteoarthritic knees with marked joint space narrowing (joint space $<3 \mathrm{~mm}$ ) in both the standing and tunnel views. The increase in the FS over an image size ranging from 0.60 to $1.08 \mathrm{~mm}$ is consistent with an increase in the cross connectivity of the vertical 

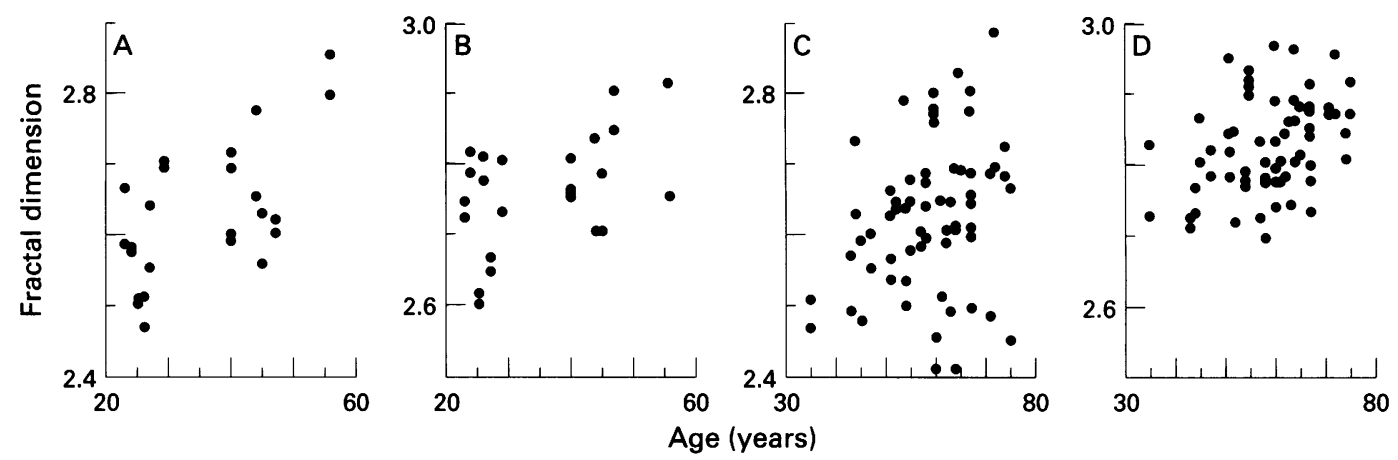

Figure 5 Graphs illustrating the correlations between the patient's age and the fractal dimension of tibial trabecular structures in the medial compartment, at a size of $0.24 \mathrm{~mm}$, for $(A)$ horizontal and $(B)$ vertical structures in non-arthritic knees; and $(\mathrm{C}$ horizontal and (D) vertical structures in osteoarthritic knees.

trabeculae and narrowing of the intertrabecular space, associated with an augmentation in the bracing and hence strength of the cancellous bone. Thus in osteoarthritic knees with more advanced disease, involving a generalised loss of cartilage from the tibia and both inferior and popliteal surfaces of the femur, the increased load upon the subchondral bone resulted in trabecular remodelling of both horizontal and vertical trabeculae.

Knees with marked joint space narrowing in the tunnel view only (subgroup 4), that is, with definite cartilage loss over the popliteal surface of the femur, showed a different pattern of subchondral cancellous bone organisation in the medial compartment of the tibia. Here, the FS for the image of the vertical structure over a size ranging from 0.60 to $1.08 \mathrm{~mm}$ was greater than in other knees, indicating a significant increase in trabecular cross connectivity and a narrowing of the space between the trabeculae. Such remodelling of the cancellous bone may result from a different pattern of joint loading associated with the loss of cartilage in the bent knee position.

In this study, no evidence was found of subarticular bone loss or osteopenia observed in animals at the early stages of experimentally induced osteoarthritis. ${ }^{30}{ }^{31}$ It is not known whether such thinning of the subchondral trabeculae forms a part of the disease process in human knee osteoarthritis. Such evidence might be obtained from patients with knee injury such as those with meniscal damage or anterior cruciate ligament rupture, but is less likely in knees of patients with idiopathic disease, since the time of onset of the degenerative changes is known in the former and is difficult to determine in the latter. Nevertheless, the existence of a subarticular osteopenia in the initial stages of human knee osteoarthritis must remain speculative since recent work ${ }^{32}$ has shown that this phenomenon in certain animal models of osteoarthritis is due to hyperaemia following the surgical intervention and trauma required to produce joint instability.

Age related changes occurred in both the medial and lateral compartments of the tibia at structure sizes $0.18 \mathrm{~mm}$ to $0.30 \mathrm{~mm}$, which are different to the scales of those structures associated with osteoarthritis. With increasing age of all subjects, both arthritic and non-arthritic, there is a significant increase in the number of fine horizontal and vertical trabeculae. The dimensions of these fine trabeculae were exactly the same in both groups, suggesting a similar age related association, in spite of the younger age of the non-arthritic reference group. Similar age related changes have been found in the horizontal trabeculae from an FSA of the lumbar spine of postmenopausal women. ${ }^{33}$ To confirmation such an association would require a larger study of subjects with a greater age range than that described here. Although age related changes have been described in vertebral cancellous bone, ${ }^{23}{ }^{34}{ }^{35-36}$, we are unaware of similar descriptions for radiographic changes in the proximal tibia. The high spatial resolution $(<50 \mu \mathrm{m})$ and primary magnification obtained with microfocal radiography have made it possible to show that within the age range of the subjects (25-75 years), very fine horizontal and vertical trabeculae, not detected by conventional radiography, were more numerous in older than in younger people. The differences observed in the FS for vertical and horizontal trabecular structures between the medial and lateral compartments of the tibia were not clear, however. It remains to be determined whether this has anything to do with the differences in the pattern of load transmission across the two compartments of the joint.

No correlation was found between the subject's body weight and changes in the subarticular cancellous bone organisation of the tibia, in either the osteoarthritic or nonarthritic subjects. This negative finding was surprising in view of the known association between obesity and knee osteoarthritis, ${ }^{37}$ and from the correlation we had previously established, using FSA, between the coarse vertical trabecular structures and overall body weight in the lumbar spine of postmenopausal women..$^{33}$ Although, more work needs to done with a larger group of patients and a carefully designed study, the result does raise the question whether systemic factors ${ }^{29} 3839$ rather than mechanical load per se may be a more important risk factor in knee osteoarthritis.

In summary, FSA quantifies the macroradiographic image of horizontal and vertical trabecular structures in the medial diseased compartment of the tibia in osteoarthritic knees. The changes in trabecular remodelling correlated with the degree of joint space narrowing measured in the same compart- 


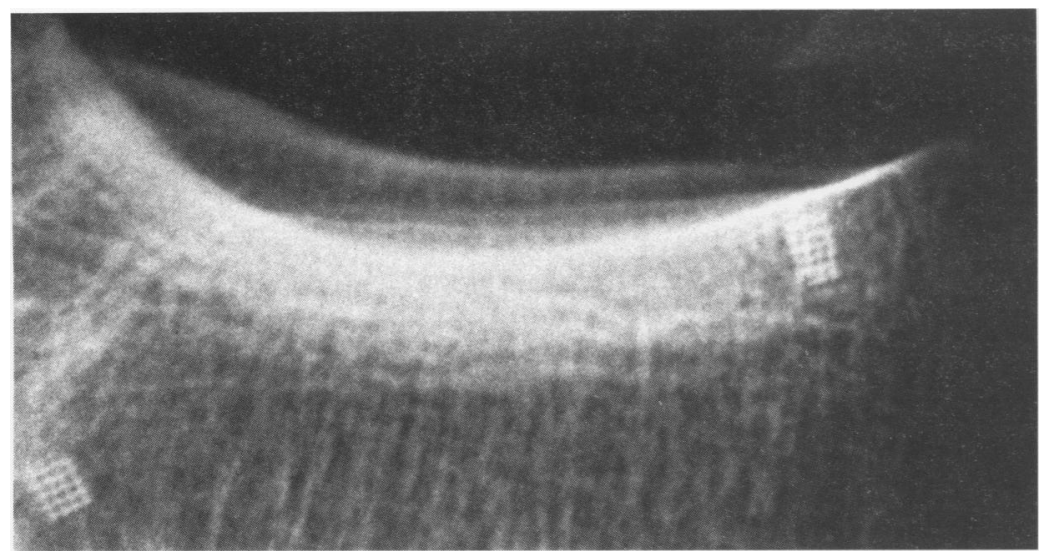

Figure 6 Part of a macroradiograph of an osteoarthritic knee joint showing marked subchondral sclerosis with an increase in the thickness of the subchondral cortex and of the subjacent horizontal trabeculae resulting in the ladder like appearance in the macroradiography (original magnification $\times 5$, reproduced $\times 3.3$ ).

ment. FSA showed that with increasing age of the subject a rise in the number of fine trabeculae occurred in the proximal end of the tibia. No correlation was found between the subject's body weight and changes in the tibial subarticular cancellous bone organisation. Although these results are encouraging, further studies are needed to provide more information on the precise relation between FSA of the macroradiographic image and the structural organisation of bone, and between changes in cartilage, subchondral cortex, and the subjacent cancellous bone to promote our understanding of the interplay between these tissue compartments and their role in osteoarthritis.

This work was supported by a grant from The Wellcome Trust We would like to thank Sally Bryant and Judy Vlahovic for their help with radiography and Kevin Fitzpatrick and Sarah Smith for photographic assistance.

1 Lequesne M, Brandt K, Bellamy R, Moskowitz R, Menkes CJ, Pelletier JP. Guidelines for testing slow acting drugs in $O A$. Proceedings of the Vth joint WHO and IIAR meeting $\mathcal{F}$ Rheumatol 1994;21 (suppl 41):65-73.

2 Sokoloff $\mathrm{L}$. Loading and motion in relation to ageing and degeneration of joints: implications for prevention and degeneration of joints: implications for prevention and treatment of osteoarthritis. In: Helminen HJ, Kiviranta 1 , Saamanen A-M, Tammi M, Paukkonen $\mathrm{K}$, Jurvelin J, eds. foint loading: biology and healt

John Wright, 1987:412-24.

Mankin HJ, Brandt KD. Pathogenesis of osteoarthritis. In Kelley WN, Harris ED, Ruddy S, Sledge CB, eds. Textbook of rheumatology, 4th ed. Philadelphia: WB Saunders, 1993

4 Resnick D, Niwayama G. Degenerative disease of extrasp nal locations. In: Resnick D, Niwayama G, eds. Diagnosis of bone and joint disorders,

5 Mow VC, Setton LA, Ratcliffe A, Howell DS, Buckwalter JA. Structure-function relationships of articular cartilage and the effects of joint instability and trauma on cartilage function. In: Brandt $\mathrm{KD}$, ed. Cartilage changes in function. In: Brandt osteoarthritis. Indianapo

6 Shahid MS, Gosling J, Shepstone L, Watt I, Dieppe P. Dual energy $\mathrm{x}$-ray absorbtiometry (DXA) of the knee joint ?. $\mathrm{Br}$ f Rheumatol 1995;34(suppl 1):122.

7 Chevalier F, Laval-Jeantet AM, Laval-Jeantet M, Bergot C. CT image analysis of the vertebral trabecular network in vivo. Calcif Tissue Int 1992;51:8-13.

8 Caligiuri P, Giger M, Favus MJ, Jia H, Doi K, Dixon LB. Computerised radiographic analysis of osteoporosis: preliminary evaluation. Radiology 1993;186:471-4.

9 Buckland-Wright JC. A new highdefinition microfocal $\mathrm{X}$-ray unit. $\mathrm{Br} \mathcal{F}$ Radiol 1989;62:201-8.

10 Buckland-Wright JC, Bradshaw CR. Clinical applications of high-definition microfocal radiography. Br $\mathcal{F}$ Radiol 1989; 62:209-17.

11 Lynch JA, Hawkes DJ, BucklandWright JC. Analysis of texture in macroradiographs of osteoarthritic knees using the fractal signature. Phys Med Biol 1991;36:709-22.
12 Lynch JA, Hawkes DJ, BucklandWright JC. A robust and accurate method for calculating the fractal signature of texture in macroradiographs of osteoarthritic knees. Med Inform 1991;16:241-51.

13 Pentland AP. Fractal based descriptions of natural scenes. IEEE Trans Pattern Analysis and Machine Intelligence 1984; 6:661-74.

14 Feder J. Fractals. New York: Plenum Press, 1988.

15 Majumdar S, Weistein RS, Prased RR, Genant HK. The fractal dimension of trabecular bone: a measure of trabecular structure. Calcif Tissue Int 1993;52:168.

16 Lynch JA, Buckland-Wright JC, Hawes DJ, Nair SV. Changes in anisotropy of modelled bone measured by simulated radiography and fractal signature analysis. Trans Simulated radiography and fract

17 Buckland-Wright JC, Macfarlane DG, Jasani MK, Lynch JA. Quantitative microfocal radiographic assessment of osteoarthritis of the knee from weight bearing tunnel and semi-flexed standing views. F Rheumatol 1994;21:1734 41.

18 Maquet P. Biomechanics of the knee. Berlin: Springer-Verlag, 1976.

19 Sartoris DJ, Resnick D. Plain film radiography: routine and specialized techniques and projections. In: Resnick $D$ Niwayama $\mathrm{G}$ eds. Diagnosis of bone and joint disorders, 2 nd ed. Philadelphia: WB Saunders, 1988:2-54

20 Lynch JA, Buckland-Wright JC, Macfarlane DG. Precision of joint space width measurement in knee osteoarthritis from digital image analysis of high definition macroradiographs. Osteoarthritis Cartilage 1993;1:209-18.

21 Lundahl T, Ohley WS, Kay SM, Siffert R. Fractional Brownian-motion: a maximum likelihood estimator and its application to imaging texture. IEEE Trans Med Imaging MI 1986;5:152-61.

22 Ruttimann UE, Webber RL, Hazelrig JB. Fractal dimension from radiographs of periodontal alveolar bone. A possible diagnostic indicator of osteoporosis. Oral Surg Oral Med Oral Pathol 1992;74:98-110.

23 Bergot C, Laval-Jeantet AM, Preteux F, Meunier A. Measurement of anisotropic vertebral trabecular bone loss during aging by quantitative image analysis. Calcif Tissue Int $1988 \cdot 43 \cdot 143-9$.

24 Ahlback S. Osteoarthritis of the knee: a radiographic investigation. Acta Radiol 1968;277(suppl):7-72.

25 Leach RE, Gregg T, Siber FJ. Weight bearing radiography in osteoarthritis of the knee. Radiology 1970; 97:265-8.

26 Lynch JA, Macfarlane DG, Buckland-Wright JC. Fractal signature analysis measures trabecular organisation in macroradiographs of OA knee patients. Trans Orthop Res Soc 1995;20:304.

27 Layton MW, Goldstein SA, Goulet RW, Feldkamp LA, Kubinski DJ, Bole GG. Examination of subchondral bone architecture in experimental osteoarthritis by microscopic computed axial tomography. Arthritis Rheum 1988; computed

28 Buckland-Wright JC, Macfarlane DG, Lynch JA, Clark B. Quantitative microfocal radiographic assessment of progression in osteoarthritis of the hand. Arthritis Rheum 1990;33:57-65.

29 Buckland-Wright JC, Macfarlane DG, Lynch J. Relationship between joint space width and subchondral sclerosis in the osteoarthritic hand. A quantitative microfocal radiographic study. $\mathcal{F}$ Rheumatol 1992;19:791-8.

30 Dedrick DK, Goulet RW, Huston L, Goldstein SA, Bole GG. Early bone changes in experimental osteoarthritis using microscopic computed tomography ? F Rheumatol 1991;18(suppl 27):44-5.

31 Dedrick DK, Goldstein SA, Brandt KD, O'Connor BL, Goulet RW, Albrecht M. A longitudinal study of subchondral plate and trabecular bone in cruciate-deficient dogs with osteoarthritis followed up for 54 months. Arthritis Rheum 1993;36:1460-7.

32 Gross TS, Bray RC, Doschak MR, Whol GR, Zernicke. Trauma induced joint instability elevates subchondral bone blood flow while degrading bone mechanical properties?. Trans Orthop Res Soc 1995;20:795.

33 Buckland-Wright JC, Lynch JA, Rymer J, Fogelman I. Fractal signature analysis of macroradiographs measures trabecular organization in lumbar vertebrae of postmenopausal women. Calcif Tissue Int 1994;54:106-12.

34 Parfitt AM. Trabecular bone architecture in the pathogenesis and prevention of fracture. Am $\mathcal{F}$ Med 1987;82(suppl 1B):68-72.

35 Atkinson PJ. Variation of trabecular structure of vertebrae with age. Calcif Tissue Res 1967;1:24-32.

36 Mosekilde L. Age related changes in vertebral trabecular bone architecture-assessed by a new method. Bone 1988; 9:247-50.

37 Felson DT, Anderson J, Naimark A, Walker AM, Meenan RF. Obesity and knee osteoarthritis. Ann Intern Med 1988; 109:18-24.

38 Harper P, Nuki G. Genetic factors in osteoarthritis. In: Nuki $\mathrm{G}$, ed. The aetiopathogenesis of osteoarthritis. Tunbridge Wells: Pitman, 1980:184-201.

39 Williams C, Jimenez SA. Molecular biology of heritable cartilage disorders. In: Kuettner KE, Goldberg VM, eds. Osteoarthritic disorders. Rosemont: American Academy of Orthopaedic Surgeons, 1995:35-50. 